\title{
Management of an uncommon form of type 2M VWD: a single centre experience
}

Sabia Rashid, Patricia Bignell, David Keeling, Nicola Curry

We report a single centre's experience of the diagnosis and management of an uncommon form of type 2 von Willebrand disease (VWD) in members of two unrelated families. The affected patients presented with mild to moderate bleeding phenotypes and accompanying MCMDM-1 VWD bleeding assessment tool scores of 5 or less. Genetic analysis in both families confirmed a missense mutation in exon 30 of the von Willebrand factor (VWF) gene, a single base substitution $T>A$ at nucleotide 5282 which led to change at codon 1761 from methionine to lysine (M1761K). This mutation lies within the $A 3$ domain of the VWF protein, a region that is important for collagen binding. All affected patients were found to have normal coagulation profiles, normal VWF multimers and normal VWF assays except the VWF collagen-binding (VWF: CB) assay levels, which were significantly reduced. Desmopressin effected a good response in all treated patients, with a 3- to 5-fold rise of VWF:CB levels. However, there was variability in the degree to which VWF:CB levels remained elevated. Surgical procedures, including the delivery of one patient, were able to be managed with either desmopressin and/or tranexamic acid alone, with little need for recourse to VWF factor concentrate therapy.

Keywords: von Willebrand disease, bleeding, collagenbinding defect, $\mathrm{A} 3$ domain

Von Willebrand factor (VWF) is a large multimeric plasma glycoprotein that serves as a carrier for coagulation factor VIII (FVIII) and mediates platelet adhesion to subendothelial collagen at the site of vascular injury [1-4]. The VWF gene is large, extending over 178 kilobases on chromosome 12, and is composed of 52 exons, encoding a large precursor protein of 2813 amino acids. Several hundred mutations have been described in patients with VWD [5]; there is increasing interest in identifying these mutations and a growing understanding of how these mutations correlate with clinical phenotype. Type 1 mutations, when found, are usually missense mutations, whereas type 3 VWD is due to

Sabia Rashid, Oxford Haemophilia \& Thrombosis Centre, Oxford University Hospitals NHS Trust, Churchill Hospital, Oxford, UK

David Keeling, Oxford Haemophilia \& Thrombosis Centre, Oxford University Hospitals NHS Trust, Churchill Hospital, Oxford, UK

Nicola Curry, Oxford Haemophilia \& Thrombosis Centre, Oxford University Hospitals NHS Trust, Churchill Hospital, Oxford, UK. E-mail: nicola.curry@ ouh.nhs.uk

Patricia Bignell, Molecular Genetics Laboratory, Oxford University Hospitals NHS Trust, John Radcliffe Hospital, Oxford, UK

www.haemjournal.com

47 homozygosity for null mutations. In both cases, mutations are found throughout the VWF gene. Type 2 mutations are more often restricted to specific VWF functional domains. Of relevance to this report, two collagen-binding domains are found within the VWD protein; the A3 domain and the A1 domain (which bind collagen types I and III, and collagen types IV and VI respectively) [6]. We report a single centre's experience of managing several patients from two unrelated families found to have the same uncommon, phenotypically mild to moderate form of type $2 \mathrm{M} \mathrm{VWD.}$

\section{Methods}

Blood tests taken for standard coagulation and VWF assays and were analysed as follows: $2.7 \mathrm{~mL}, 9: 1 \mathrm{vol} / \mathrm{vol} 0.109 \mathrm{M}$ buffered sodium citrate, 3.2\% (Becton Dickinson, Plymouth, UK). Prothrombin times (STA ${ }^{\circledR}$ Neoplastine ${ }^{\circledR}$ R, Stago, Reading, UK) and activated partial thromboplastin times (TriniCLOT aPTT HS, Trinity Biotech, North Carolina, US) were processed using the STA-R evolution ${ }^{\circledR}$ analyser (Stago Diagnostica, UK) analyser according to standard protocols. FVIII:C was analysed by a chromogenic method (Siemens Berichrom FVIII chromogenic assay, London, UK); VWF:Ag was measured by a latex immunoassay method (VWF-LIA latex immunoassay, Stago, UK) and VWF:CB was performed using the Corgenix assay (Quadratech Diagnostics, Epsom, UK). The CBA ELISA method employed used equine tendon collagen types I (95\%) and III (5\%). The VWF:RCo was measured using an automated system with the CS2100 Sysmex coagulometer (BC VWF reagent, Siemens, London, UK). PFA-100 (Dade- Behring, Switzerland) closure times were determined according to the manufacturer's instructions. VWF multimer composition was assessed by sodium dodecyl sulphate agarose gel electrophoresis, followed by Western blotting and detection with rabbit anti-human VWF antibody, and porcine anti-rabbit HRP conjugate. The gel was visualised using a Bio-Rad AP substrate kit (Bio-Rad Laboratories Ltd, Hemel Hempstead, UK). Sequencing of the VWF gene was undertaken; the DNA sample was amplified using 51 exon-specific primers and the product was sequenced using an ABI3700. Sequencing results were analysed using Mutation Surveyor, DNA Variant Analysis Software (Softgenetics, Pennsylvania, US).

\section{Case report}

Family 1: A young woman aged 21 (Proband 1) was referred to the haemophilia centre for investigation of menorrhagia, with onset at the menarche. It transpired that all of the 
Table 1: Main haemostatic findings observed in Family 1

\begin{tabular}{|c|c|c|c|c|c|c|c|c|c|c|c|c|}
\hline ID & Gender & $\begin{array}{l}\text { Bleeding } \\
\text { Score }\end{array}$ & $\begin{array}{l}\text { Blood } \\
\text { Group }\end{array}$ & $\begin{array}{c}\text { VWF } \\
\text { multimers }\end{array}$ & $\begin{array}{c}\text { PFA Col/ } \\
\text { ADP }\end{array}$ & $\begin{array}{c}\text { PFA } \\
\text { Col/Epi }\end{array}$ & FVIII:C & VWF:Ag & VWF:RCo & $\begin{array}{c}\mathrm{RCo}: \mathrm{Ag} \\
\text { ratio }\end{array}$ & VWF:CB & $\begin{array}{c}\mathrm{CB}: \mathrm{Ag} \\
\text { ratio }\end{array}$ \\
\hline & & & & & $\begin{array}{c}55-122 \\
\text { sec }\end{array}$ & $\begin{array}{c}79- \\
164 \mathrm{sec}\end{array}$ & $\begin{array}{l}0.5-2.0 \\
\mathrm{IU} / \mathrm{mL}\end{array}$ & $\begin{array}{l}0.5-2.0 \\
\mathrm{IU} / \mathrm{mL}\end{array}$ & $\begin{array}{l}0.5-2.0 \\
\mathrm{IU} / \mathrm{mL}\end{array}$ & $>0.6$ & $\begin{array}{c}0.5-2.0 \\
I U / \mathrm{mL}\end{array}$ & $>0.6$ \\
\hline Proband & $F$ & 5 & O & Normal & 66 & 131 & 1.23 & 0.78 & 0.81 & 1.03 & 0.27 & 0.35 \\
\hline Mother & $\mathrm{F}$ & 2 & A & Normal & 77 & 99 & 1.50 & 1.02 & 0.88 & 0.86 & 0.38 & 0.37 \\
\hline Sister 1 & $\mathrm{~F}$ & 4 & $A$ & Normal & 67 & 75 & 2.95 & 2.31 & 1.80 & 0.78 & 0.79 & 0.34 \\
\hline Sister 2 & $F$ & 3 & A & - & 74 & 88 & 2.42 & 1.70 & 1.68 & 0.99 & 0.41 & 0.24 \\
\hline
\end{tabular}

Reference values are given for each assay. Ratios of antigen to activity are shown adjacent to activity columns. VWF indicates von Willebrand factor; Ag, antigen; RCo, ristocetin cofactor activity; CB, collagen-binding activity; FVIII:C, factor 8 activity; Col/ADP, collagen/ADP induced closure time; and $\mathrm{Col} /$ Epi, collagen/epinephrine induced closure time. Bleeding scores were calculated using the condensed MCMDM-1VWD questionnaire.

female members of her family had menorrhagia, which affected a mother, aged 46, and all three of her daughters, aged 21, 19 and 16 years. On further questioning, it was ascertained that the mother had bled for several days following a dental extraction, but had not bled following three spontaneous vaginal deliveries. The daughters had additional symptoms of easy bruising, regular gum bleeding during teeth-brushing, and epistaxis lasting up to 30 minutes but not needing hospital admission. None had suffered with iron deficiency or had required a blood transfusion. Bleeding scores were calculated [7]. The mother was noted to have six siblings with 18 children between them, but none had taken up the offer of coagulation or genetic testing.

Routine blood tests were drawn, including FBC, standard coagulation and von Willebrand assays. Results of the blood tests for Family 1 are shown in Table1. All results, including platelet count, PT and APTT (data not shown) were normal, as were all VWF assays, with the exception of the von Willebrand collagen-binding activity (VWF:CB), which was markedly reduced in all family members. VWF:CB: VWF:Ag ratios ranged between 0.24 and 0.37 (normal >0.6). Sister 1 had high VWF: Ag at the time of testing, which was attributed to the stress of the blood draw. DNA sequencing in all family members confirmed a heterozygous missense mutation in exon 30 of the VWF gene, a single base substitution $T>A$ at nucleotide 5282, which led to the amino acid substitution from methionine to lysine, at codon 1761; M1761K.

All three daughters were treated for menorrhagia with tranexamic acid and the combined oral contraceptive pill, to good effect. Sister 1 sustained an intra-articular fracture to the right radial head, treated conservatively by the trauma team. Haemostatic management included a single subcutaneous dose of $0.3 \mathrm{mcg} / \mathrm{kg}$ desmopressin and tranexamic acid orally, 1 gram three times a day for 5 days. Resolution of the joint effusion (a normal consequence of this type of fracture) followed a normal pattern and no further haemostatic treatment was required (see Table 3 for desmopressin response results).

Sister 2 was scheduled for an elective mandibular realignment procedure with osteotomy, as surgical treatment for micrognathia. She was treated with 0.3 microgram $/ \mathrm{kg}$ desmopressin 90 minutes pre-operatively and $1 \mathrm{~g}$ tranexamic acid intravenously at induction of anaesthesia. VWF:CB levels rose from $0.23 \mathrm{IU} / \mathrm{mL}$ predesmopressin to $0.57 \mathrm{IU} / \mathrm{mL}$ at 90 minutes. Blood loss intra- and post-operatively was minimal. The initial surgery, unfortunately, did not provide a good aesthetic result and a second procedure was planned two days later. In light of concerns about an increased chance of bleeding

\section{Table 2: Main haemostatic findings for Family 2}

\begin{tabular}{|c|c|c|c|c|c|c|c|c|c|c|c|c|}
\hline ID & Gender & $\begin{array}{l}\text { Bleeding } \\
\text { Score }\end{array}$ & $\begin{array}{l}\text { Blood } \\
\text { Group }\end{array}$ & $\begin{array}{c}\text { VWF } \\
\text { multimers }\end{array}$ & $\begin{array}{c}\text { PFA Col/ } \\
\text { ADP }\end{array}$ & $\begin{array}{c}\text { PFA } \\
\text { Col/Epi }\end{array}$ & FVIII:C & VWF:Ag & VWF:RCo & $\begin{array}{c}\mathrm{RCo}: \mathrm{Ag} \\
\text { ratio }\end{array}$ & VWF:CB & $\begin{array}{c}\text { CB:Ag } \\
\text { ratio }\end{array}$ \\
\hline & & & & & $\begin{array}{c}55-122 \\
\text { sec }\end{array}$ & $\begin{array}{c}79- \\
164 \mathrm{sec}\end{array}$ & $\begin{array}{c}0.5-2.0 \\
\mathrm{IU} / \mathrm{mL}\end{array}$ & $\begin{array}{l}0.5-2.0 \\
\mathrm{IU} / \mathrm{mL}\end{array}$ & $\begin{array}{c}0.5-2.0 \\
I U / m L\end{array}$ & $>0.6$ & $\begin{array}{l}0.5-2.0 \\
\mathrm{IU} / \mathrm{mL}\end{array}$ & $>0.6$ \\
\hline Proband & M & $1^{*}$ & O & Normal & - & - & 1.35 & 1.28 & 1.20 & 0.94 & 0.20 & 0.15 \\
\hline Mother & $\mathrm{F}$ & 4 & A & Normal & 57 & 97 & 1.39 & 1.04 & 0.94 & 0.90 & 0.24 & 0.23 \\
\hline $\begin{array}{c}\text { Aunt } \\
(12 / 40)\end{array}$ & $F$ & 5 & O & - & - & - & 1.00 & 1.07 & 1.07 & 1.00 & 0.13 & 0.12 \\
\hline $\begin{array}{c}\text { Aunt } \\
(28 / 40)\end{array}$ & & & & - & - & - & 2.00 & 1.82 & 2.04 & 1.12 & 0.46 & 0.25 \\
\hline Cousin & $\mathrm{F}$ & - & - & - & - & - & - & 1.31 & 1.25 & 0.95 & 0.27 & 0.22 \\
\hline
\end{tabular}

Reference values are given for each assay. Ratios of antigen to activity are shown adjacent to activity columns. VWF indicates von Willebrand factor; $\mathrm{Ag}$, antigen; RCO, ristocetin cofactor activity; CB, collagen-binding activity; FVIII:C, factor 8 activity; Col/ADP, collagen/ADP induced closure time; and $\mathrm{Col} /$ Epi, collagen/epinephrine induced closure time. 12/40 and 28/40 indicates the gestation at which blood samples were drawn. Bleeding scores were calculated using the condensed MCMDM-1VWD questionnaire. Note*: the proband has not faced any significant haemostatic challenges. 
Table 3: Haemostatic responses in affected individuals following a therapeutic DDAVP trial

\begin{tabular}{|c|c|c|c|c|c|c|c|c|}
\hline \multirow[t]{2}{*}{ ID } & \multirow{2}{*}{$\begin{array}{l}\text { Family } \\
\text { number }\end{array}$} & \multirow{2}{*}{$\begin{array}{l}\text { Blood } \\
\text { Group }\end{array}$} & \multirow[t]{2}{*}{ Timing of blood sampling } & FVIII:C & VWF:Ag & VWF:RCo & VWF:CB & $\mathrm{CB}: \mathrm{Ag}$ ratio \\
\hline & & & & $\begin{array}{l}0.5-2.0 \\
\mathrm{IU} / \mathrm{mL}\end{array}$ & $\begin{array}{l}0.5-2.0 \\
\mathrm{IU} / \mathrm{mL}\end{array}$ & $\begin{array}{c}0.5-2.0 \\
\mathrm{IU} / \mathrm{mL}\end{array}$ & $\begin{array}{l}0.5-2.0 \\
\mathrm{IU} / \mathrm{mL}\end{array}$ & $>0.6$ \\
\hline \multirow[t]{3}{*}{ Proband } & \multirow[t]{3}{*}{1} & \multirow[t]{3}{*}{$\mathrm{O}$} & Pre-DDAVP & 1.07 & 0.73 & 0.88 & 0.10 & 0.13 \\
\hline & & & 80 min post & 2.01 & 3.32 & 2.27 & 0.48 & 0.14 \\
\hline & & & $5.3 \mathrm{~h}$ post & 1.83 & 1.57 & 1.83 & 0.22 & 0.14 \\
\hline \multirow[t]{2}{*}{ Sister 2} & \multirow[t]{2}{*}{1} & \multirow[t]{2}{*}{ A } & Pre-DDAVP & 1.14 & 0.95 & 1.04 & 0.23 & 0.24 \\
\hline & & & 90 min post & 2.74 & 1.89 & 2.25 & 0.57 & 0.30 \\
\hline \multirow[t]{3}{*}{ Mother } & \multirow[t]{3}{*}{2} & \multirow[t]{3}{*}{ A } & Pre-DDAVP & 1.53 & 1.09 & 1.14 & 0.35 & 0.32 \\
\hline & & & 120 min post & 3.22 & 2.59 & 2.52 & 0.99 & 0.38 \\
\hline & & & $5.3 \mathrm{~h}$ post & 3.72 & 2.49 & 2.22 & 0.79 & 0.32 \\
\hline
\end{tabular}

Reference values are given for each assay. Ratios of antigen to VWF:CB activity are shown. VWF indicates von Willebrand factor; Ag, antigen; RCo, ristocetin cofactor activity; CB, collagen-binding activity; and FVIII:C, factor 8 activity.

at re-exploration surgery, the increased length of surgery (4 hours), further requirements for intravenous fluids and an inability to drink following the procedure, 2000 units Voncento (human factor VIII/VWF concentrate) was given for the second procedure. Blood loss was, again, minimal.

Family 2: The first member of the second family to be diagnosed was a 12-week-old boy (Proband 2), referred with unexplained easy bruising. The child was born at term, had no dysmorphic features and no other bleeding history. Further questioning of the family revealed that the child's mother had easy bruising. She also reported menorrhagia and had suffered increased blood loss after the birth of all three of her children, requiring oral iron and tranexamic acid. She reported that her own mother had easy bruising, epistaxis and had undergone a hysterectomy for menorrhagia. Bleeding scores were calculated retrospectively from the notes [7]. Blood tests were taken for standard coagulation and VWF assays; results are shown in Table 2. The mother went on to have a desmopressin trial prior to minor surgery; results are shown in Table 3. Genetic analysis confirmed the M1761K mutation in exon 30 of the VWF gene.

Another family member, the aunt of the proband, was referred in the first trimester of her third pregnancy. By the time of referral she had had two children. Both were delivered vaginally; she reported increased bleeding after both and tranexamic acid therapy was required. She also gave a history of easy bruising and menorrhagia from the menarche. Blood tests at 12 weeks gestation showed a FVIII level of $1.0 \mathrm{lU} / \mathrm{mL}$, VWF: Ag 1.07 IU/mL, VWF:RCo $1.07 \mathrm{lU} /$ $\mathrm{mL}$ and $\mathrm{VWF}: C B 0.13 \mathrm{IU} / \mathrm{mL}$. An Arabin suture was placed at 24 weeks gestation as treatment for a shortened cervix and a previous history of premature labour. This was covered with tranexamic acid, 1 gram three times a day for 3 days. Repeat tests at 30 weeks showed FVIII $2.0 \mathrm{IU} / \mathrm{mL}$, VWF:Ag $1.82 \mathrm{IU} / \mathrm{mL}$, VWF:RCo $2.04 \mathrm{IU} / \mathrm{mL}$ and VWF:CB $0.46 \mathrm{IU} /$ $\mathrm{mL}$. A management plan for her delivery was formulated at this time point due to the high expectation of a premature labour. Recommendations to avoid high or mid rotational forceps, ventouse extraction and foetal scalp electrodes were given.

At the time of delivery (34 weeks gestation), the aunt was treated with tranexamic acid 1gm IV during established labour and delivered a baby girl (cousin to the proband), with blood loss of approximately $250 \mathrm{~mL}$. She received tranexamic acid, 1 gram three times a day, for 28 days post-partum. At six weeks post-partum, the aunt reported minimal blood loss with blood stained lochia for 3 weeks only. She maintained a normal haemoglobin level and had no evidence of iron deficiency. The baby's cord sample showed VWF:Ag $1.31 \mathrm{IU} / \mathrm{mL}$, VWF:RCo $1.25 \mathrm{IU} / \mathrm{mL}$ and $V W F: C B \quad 0.27 \mathrm{IU} / \mathrm{mL}$. DNA testing confirmed the baby had inherited the familial VWF mutation.

\section{Discussion}

We report the diagnosis, management and treatment of an uncommon form of type 2 VWD. The laboratory phenotype was characterised by a markedly low von Willebrand factor collagen-binding activity, with normal levels of all other VWF assays and normal VWF multimers. The VWF:CB levels varied between and within the two families. The intrafamilial variation is, in part, likely due to the influence of the $A B O$ blood group, family members with blood group $O$ having lower VWF levels. DNA sequencing analysis showed a missense mutation in exon 30 of the VWF gene in all affected members of the two unrelated families, one of which was previously reported in a letter [8]. A single base substitution T>A at nucleotide 5282 was detected, which resulted in an M1761K amino-acid substitution. The clinical phenotype of the affected family members was relatively mild, with the highest bleeding scores being 5 in both families; surgical haemostasis was most often achieved with desmopressin or tranexamic acid, rather than requiring VWF factor concentrate.

Affected patients had symptoms of easy bruising, selflimiting epistaxis, bleeding after dental extractions and 
menorrhagia. None had required hospital admissions or blood transfusion for their bleeding symptoms. The female patients suffered mild to moderate post-partum blood loss and were managed effectively with tranexamic acid. During the single pregnancy managed at the centre, VWF:CB levels were documented to rise throughout gestation and delivery was managed with tranexamic acid alone.

Desmopressin is known to provide good haemostatic cover for treatment of mucocutaneous bleeding and to prevent bleeding at the time of invasive procedures for some patients with VWD [8-9]. In the two reported families, we found a good immediate response to desmopressin therapy (with levels rising between 3 and 5 fold), but variability was observed in how well the response was sustained, with more rapid falls seen in blood group O patients. However, clinically, patients appeared to respond well to desmopressin, with no excess bleeding following interventions. Desmopressin should therefore be considered as a potential treatment option for haemostatic management in similar patients and all patients should undergo a therapeutic trial.

The collagen binding site has been localised to the A1 and $A 3$ domains of the VWD protein [8]. The VWF A3 domain (formed by the amino acid residues 1683-1874; an area covering the missense mutation reported in the two families) contains the main binding site for collagen types I and III [10]. In contrast, the A1 domain binds to collagen types IV and VI [6,12]. However, it has been recognised that the A1 domain can also bind to collagen types I and III under certain flow conditions [13,14]. The ability of VWF to bind efficiently to collagen is heavily dependent on the presence of high molecular weight VWF multimers (HMWM) [15], and low VWF:CB levels can result from either a defective A3 domain or reduced levels of HMWMs. Four mutations have been described previously in the A3 domain, all of which cause a low VWF:CB level without loss of high molecular weight VWF multimers: S1731T, W1745C, S1783A, H1786D $[15,16,17]$. The mutation cited in this report also follows this pattern [8].

The mild phenotypic nature of this collagen-binding type 2 VWD may be due to the ability of the intact VWF A1 domain to bind to collagen under shear stress [13,14], possibly compensating for the loss of binding affinity in the A3 domain, even though this does not occur under static conditions [6]. The finding of this defect in two unrelated families reiterates the importance of testing with a VWF:CB assay as well as a VWF:RCo assay when investigating a patient with a bleeding disorder in order to avoid missing the diagnosis $[8,15,18]$.

\section{Conclusion}

We report the clinical management of an uncommon type 2 VWD with a collagen-binding defect in two unrelated families. This mutation is associated with a mild to moderate bleeding phenotype, and patients can be effectively managed with desmopressin and tranexamic acid.

\section{Disclosures}

The authors have advised that there are no interests that might be perceived as posing a conflict or bias.

This is an Open Access article distributed under the terms of the Creative Commons Attribution License (http://creativecommons.org/licenses/ by/2.0), which permits unrestricted use, distribution, and reproduction in any medium, provided the original work is properly cited.

\section{References}

1. Schneppenheim R, Budde $U$. von Willebrand factor: the complex molecular genetics of a multidomain and multifunctional protein. J Thromb Haemost 2011; 9 Suppl 1: 209-15; doi: 10.1111/j.1538-7836.2011.04324.x.

2. Rodeghiero F, Castaman G, Dini E. Epidemiological investigation of the prevalence of von Willebrand's disease. Blood 1987; 69: 454-9.

3. Werner EJ, Broxson EH, Tucker EL, et al. Prevalence of von Willebrand disease in children: a multi-ethnic study. J Pediatr 1993; 123: 893-8.

4. Laffan MA, Lester W, O'Donnell JS, et al. The diagnosis and management of von Willebrand disease: a United Kingdom Haemophilia Centre Doctors Organization guideline approved by the British Committee for Standards in Haematology. Br J Haematol 2014; 167: 453-65; doi: 10.1111/bjh.13064. 5. University of Sheffield. von Willebrand factor Variant Database (VWFdb). Available from: www.vwf.group.shef.ac.uk/ (accessed 21 November 2011). 6. Flood VH, Schlauderaff AC, Haberichter SL, et al. The crucial role for the VWFA1 domain in binding to type IV collagen. Blood 2015; 125: 2297-304; doi: 10.1182/blood-2014-11-610824.

7. Tosetto A, Rodeghiero F, Castaman G, et al. A quantitative analysis of bleeding symptoms in type 1 von Willebrand disease: results from a multicenter European study (MCMDM-1 VWD). J Thromb Haemost 2006; 4: 766-73.

8. Keeling D, Beavis J, Marr R, et al. A family with type 2M VWD with normal VWF:RCo but reduced VWF:CB and a M1761K mutation in the A3 domain. Haemophilia 2012; 18:e33; doi: 10.1111/j.1365-2516.2011.02676.x.

9. Rodeghiero F, Castaman G, Tosetto A. How I treat von Willebrand disease. Blood 2009; 114: 1158-65; doi: 10.1182/blood-2009-01-153296. 10. Federici $A B$. The use of desmopressin in von Willebrand disease: the experience of the first 30 years (1977-2007). Haemophilia 2008; 14(Suppl 1): 5-14; doi: 10.1111/j.1365-2516.2007.01610.x.

11. Favaloro EJ. Von Willebrand factor collagen-binding (activity) assay in the diagnosis of von Willebrand disease: A 15-year journey. Semin Thromb Hemost 2002; 28: 191-202.

12. Lankhof $H$, van Hoeij $M$, Schiphorst $M E$, et al. $A 3$ domain is essential for interaction of von Willebrand factor with collagen type III. Thromb Haemost 1996; 75: 950-8.

13. Denis C, Baruch D, Kielty CM, et al. Localization of von Willebrand factor binding domains to endothelial extracellular matrix and to type $\mathrm{VI}$ collagen. Arterioscler Thromb 1993; 13: 398-406.

14. Bonnefoy A, Romijn RA, Vandervoort PA, et al. von Willebrand factor A1 domain can adequately substitute for $A 3$ domain in recruitment of flowing platelets to collagen. J Thromb Haemost 2006; 4:2151-61.

15. Riddell AF, Gomez K, Millar CM, et al. Characterization of $\mathrm{W} 1745 \mathrm{C}$ and S1783A: 2 novel mutations causing defective collagen binding in the A3 domain of von Willebrand factor. Blood 2009; 114: 3489-96; doi: 10.1182/ blood-2008-10-184317.

16. Sadler JE, Budde U, Eikenboom JC, et al. Working Party own von Willebrand Disease Classification. Update on the pathophysiology and classification of von Willebrand disease: a report of the Subcommittee on von Willebrand Factor. J Thromb Haemost 2006; 4: 2103-14.

17. Ribba AS, Loisel I, Lavergne JM, et al. Ser968Thr mutation within the A3 domain of von Willebrand factor (VWF) in two related patients leads to a defective binding of VWF to collagen. Thromb Haemost 2001; 86: $848-54$

18. Flood $\mathrm{VH}$, Lederman $\mathrm{CA}$, Wren JS, et al. Absent collagen binding in a VWF A3 domain mutant: utility of the VWF:CB in diagnosis of VWD. J Thromb Haemost 2010; 8: 1431-3; doi: 10.1111/j.1538-7836.2010.03869.x. 